\title{
AN APPROXIMATE CALCULATION OF ENERGY DISSIPATION AND ELECTRIC EROSION OF ELECTRODES IN THE HIGH-VOLTAGE HIGH-CURRENT AIR SWITCH OF ATMOSPHERIC PRESSURE
}

Purpose. To obtain new calculation correlations, determining approximate energy dissipation and electric erosion of massive basic metallic electrodes in the high-voltage high-current air switchboard (HVCAS) of atmospheric pressure, in-use in the bit chain of the high-voltage electrophysics setting (HVES) with the powerful capacity store of energy (CSE). Methodology. Electrophysics bases of technique of high-voltage and large impulsive currents (LIC), scientific and technical bases of development and planning of high-voltage heavy-current impulsive electro-devices, including HVES and powerful CSE, and also methods of measuring in their bit chains of LIC of the microsecond temporal range. Results. On the basis of new engineering approach the results of calculation estimation of excretions energy and electric erosion of massive basic metallic electrodes are resulted in probed HVCAS. New correlations are obtained for the approximate calculation of thermal energy, selected in an impulsive air spark and on the workings surfaces of anode and cathode of HVCAS. It is entered and a new electrophysics concept, touching equivalent active resistance of impulsive air spark, is mathematically certain. New formulas are obtained for the approximate calculation of most depth of single round crater of destruction on the workings surfaces of basic metallic electrodes of HVCAS, and also mass of metal, thrown out magnetic pressure from this crater of destruction on the electrodes of switch for one electric discharge through them powerful CSE HVES. It is shown that the radius of the indicated single crater of destruction is approximately equal to the maximal radius of plasma channel of a spark discharge between a cathode and anode of HVCAS. The executed high-current experiments in the bit chain of HVES with powerful CSE validated row of the got and in-use calculation correlations for the estimation of energy dissipation and electric erosion of metallic electrodes in examined HVCAS. Originality. New engineering approach is developed for the approximate calculation and estimation of energy dissipation and electric erosion of basic metallic electrodes in HVCAS. A formula is firstly got for approximate calculation unchanging in the process of swaying or aperiodic discharge of CSE HVES on the electric loading of active resistance of impulsive air spark between the electrodes of probed HVCAS. Practical value. Drawing on the got results in a high-voltage impulsive technique provides operative implementation of calculation of balance of electric energy in the high-current circuit of HVES with powerful CSE and point electric load, and also prognostication of the technical state of workings surfaces of massive basic metallic electrodes of HVCAS. References 21, figures 3.

Key words: high-voltage high-current air switch, dissipated thermal energy in air spark and on the electrodes of switch, electric erosion of metallic electrodes of switch, depth of single crater of destruction on the electrodes of switch, thrown out mass of metal from the single crater of destruction of electrodes of switch.

Приведены результаты применения нового инженерного подхода к расчету тепловой энергии, выделяющейся в плазменном канале искрового разряда и на массивных металлических электродах высоковольтного сильноточного воздушного коммутатора (ВСВК) атмосферного давления, используемого в составе вьсоковольтной электрофизической установки (ВЭФУ) с мощным емкостным накопителем энергии (ЕНЭ). Полученные соотношения для определения указанной энергии позволяют выполнять расчетную оценку баланса электрической энергии в разрядной цепи ВЭФУ с ЕНЭ с учетом ее тепловых потерь в ВСВК. Показано, что на основе разработанного подхода может быть выполнен расчет электрической эрозии основных металлических электродов ВСВК. Получены новые расчетные выражсения для нахождения глубины одиночного кратера разруиения на металлических электродах ВСВК и массы металла, выбрасываемой искрой из электродов исследуемого коммутатора за один разряд ЕНЭ установки. Библ. 21, рис. 3.

Ключевые слова: высоковольтный сильноточный воздушный коммутатор, выделяемая тепловая энергия в воздушной искре и на электродах коммутатора, электрическая эрозия металлических электродов коммутатора, глубина одиночного кратера разрушения на электродах коммутатора, выбрасываемая масса металла из одиночного кратера разрушения электродов коммутатора.

Introduction. It is known that the commutation of the accumulated electric energy in a high-capacity capacitive energy storage (CES) device of a highvoltage electrophysical setting (HVES) is performed by

means of a special electrical engineering device termed arrester by domestic terminology, and by foreign terminology by a switch $[1,2]$. In the future, let us dwell

(C) M.I. Baranov, S.V. Rudakov 
on the latest technical term, which has become most widely used in modern high-voltage pulse technology (HVPT). Vacuum, various gases and their mixtures, liquids and solids can be used as working dielectric media of the considered HVES discharge circuit switches with powerful CSE [1-4]. A wide application in the field of modern HVPT because of its comparative cheapness and simplicity in manufacturing has received high-voltage high-current air switches (HVCAS) of atmospheric pressure at a constant voltage up to \pm 125 $\mathrm{kV}$ and commutated pulse currents up to $\pm 1 \mathrm{MA}$ amplitude [1, 5-7]. As a rule, the main electrodes of HVCAS are made of medium and refractory metals (for example, steel and molybdenum) or metal compositions (for example, «tungsten-copper» compositions) [1, 3-7]. One of the drawbacks of these HVCAS is the increased electroerosive wear of the working surfaces of their main metal electrodes, caused by the intense exposure of the high-power heat flux of the plasma channel of the spark discharge in the areas of its binding at the electrodes of such switches. In this connection, for HVCAS, the actual tasks are those related to the calculation estimation in such high-current heat loss in switches in the plasma spark channel and on the main electrodes of the HVCAS, as well as the electrical erosion of the working surfaces of their main metal electrodes.

The goal of the paper is obtaining new calculation relationships that determine in an approximate form the energy dissipation and electrical erosion of massive metal main electrodes in the HVCAS used in the discharge circuits of a number of HVES with the CSE.

1. Research objective definition. Let us consider the HVES discharge circuit with a powerful CSE and an actively inductive load, switching large impulse current (LIC) in which the HVCAS performs with massive uniform base metal electrodes of a hemispherical shape-the cathode and the anode (Fig. 1). We suppose that these electrodes of HVCAS located in atmospheric air under normal conditions (air pressure is $1.013 \cdot 10^{5} \mathrm{~Pa}$ and its temperature is equal to $\theta_{0}=0{ }^{\circ} \mathrm{C}$ [8]) at the distance $l_{k}$ from each other form a two-electrode system (TES). Let the radius $R_{e}$ of the working surfaces of the cathode and the anode of the considered HVCAS exceeds the penetration depths in their conductive materials of the electromagnetic and thermal fields created by a cylindrical channel of a spark discharge of radius $r_{c}<R_{e}$ in the areas of its binding on the working surfaces of the electrodes of the investigated HVCAS.

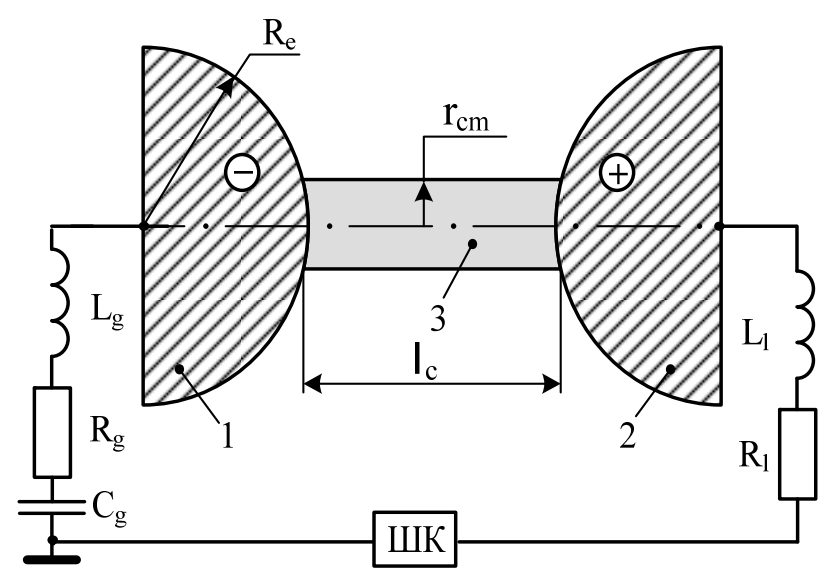

Fig. 1. The principal electrical circuit of the HVES discharge circuit with a powerful CSE and a high-voltage high-current two-electrode air switch (1,2 - massive metal cathode and anode of HVCAS of hemispherical shape with an outer radius $R_{e} ; 3$ - plasma high-current channel of an air spark discharge with length $l_{c}$ and maximum radius $r_{c m} ; R_{g}, L_{g}, C_{g}$ - the own electrical parameters of the HVES with CSE; $R_{l}, L_{l}-$ the own electrical parameters of the active-inductive load; ШК - the measuring coaxial ШК-300 shunt designed to measure a microsecond pulse current with an amplitude of $I_{m}$ up to $\pm 300 \mathrm{kA}$ with its action integral $J_{a}$ up to $\left.2.5 \cdot 10^{6} \mathrm{~J} / \Omega[9,10]\right)$

In this connection we assume that the working surfaces of these electrodes of the HVCAS of the highcurrent spark in the zones of fastening of the highcurrent spark in the first approximation will be close to flat. We assume that in the TES of the switchboard, the length $l_{c}$ of the plasma spark channel is equal to the minimum length $l_{k}$ of the interelectrode gap in the HVCAS. We assume that the heat flux density $g_{c}(t)$ and the density $\delta_{d}(t)$ of the discharge current $i_{d}(t)$ of the HVES with CSE in the cylindrical spark discharge channel for the investigated HVCAS are practically uniformly distributed over its transverse circular cross section with a time-varying in $t$ radius $r_{c}$. One of the confirmations to this can be the fact that in a highcurrent plasma channel of a gas discharge thermodynamic electron and ion temperatures are characterized by a practically uniform distribution in its current radius $r_{c}$ [11]. We use the assumption that the holes (craters) of failure appearing in the areas of binding of the plasma channel of the spark discharge on the working surfaces of the anode and the cathode of the HVCAS have a geometric shape close to the shape of the spherical segment $[12,13]$. It is required, within the proposed engineering approach, to obtain new relationships for the approximate calculation of the energy release and electrical erosion of massive metal electrodes in the HVCAS of the HVES discharge circuit with powerful CSE, and also to perform in a high-voltage laboratory using a powerful capacitortype generator that generates, on the $R L$-load, a microsecond range, experimental verification of the performance of some of these relationships. 
2. Approximate calculation of the energy dissipation in the HVCAS of the discharge circuit of the HVES with CSE. First, let us dwell on the estimated evaluation of the thermal energy $W_{c}$, which is dissipated directly in the plasma channel of the air spark discharge, which arises between the metal electrodes of the HVCAS. Proceeding from the known positions of electro- and thermophysics, the expression for $W_{c}$ can be represented in the following form:

$$
W_{c}=R_{c} J_{a}
$$

where $J_{a}=\int_{0}^{\infty} i_{d}^{2}(t) d t$ is the action integral of the pulsed current $i_{d}(t)$ in the discharge circuit of the HVES with $\mathrm{CSE} ; R_{c}$ is the equivalent active resistance of the plasma channel of the air spark in the switch.

Next, let us determine the calculation in (1) of the action integral $J_{a}$ of the current flowing in the HVES discharge circuit with CSE through the investigated HVCAS. In the case of a change in the current $i_{d}(t)$ according to the law of an exponentially damped sinusoid, which has the analytical form $i_{d}(t)=k_{d s} I_{m s} \exp (-\delta t) \sin (\omega t)$, the following calculation relation can be used for the action integral $J_{a}$ of the discharge current in the HVES circuit with a powerful CSE:

$$
J_{a}=0.25 k_{d s}^{2} I_{m s}^{2} \delta^{-1}\left[(\delta / \omega)^{2}+1\right]^{-1},
$$

where $I_{m s}$ is the first amplitude of the discharge circuit $i_{d}(t)$ changing with angular frequency $\omega$ and the attenuation coefficient $\delta$ in the high-current circuit of the HVES with CSE;

$k_{d s}=\left[\exp \left(-\delta \omega^{-1} \operatorname{arcctg} \delta \omega^{-1}\right) \sin \left(\operatorname{arcctg} \delta \omega^{-1}\right)\right]^{-1}$ is the normalizing coefficient for a current varying in time $t$ according to the law of a damped sinusoid [14].

In the case of a change in the discharge current, $i_{d}(t)$ by aperiodic law having the analytical form $i_{d}(t)=k_{d a} I_{m a}\left[\exp \left(-\alpha_{1} t\right)-\exp \left(-\alpha_{2} t\right)\right]$, the calculated ratio for the action integral $J_{a}$ in the HVES discharge circuit with CSE will have the following view:

$$
J_{a}=0.5 k_{d a}^{2} I_{m a}^{2}\left\lfloor\alpha_{1}^{-1}+\alpha_{2}^{-1}-4\left(\alpha_{1}+\alpha_{2}\right)^{-1}\right\rfloor,
$$

where $I_{m a}$ is the amplitude of the unipolar pulse current $i_{d}(t)$ with coefficients of the temporal shape $\alpha_{1}$ and $\alpha_{2}$; $k_{d a}=\left[\left(\alpha_{1} / \alpha_{2}\right)^{\alpha_{1} /\left(\alpha_{2}-\alpha_{1}\right)}-\left(\alpha_{1} / \alpha_{2}\right)^{\alpha_{2} /\left(\alpha_{2}-\alpha_{1}\right)}\right]^{-1}$ is the normalizing coefficient for the impulse current of the HVES, which varies aperiodically with time $t$ [14].

In the practical application of (3), it should be borne in mind that $\alpha_{1} \approx 0.76 / \tau_{p}$ and $\alpha_{2} \approx 2.37 / \tau_{f}$, [14], where $\tau_{f}, \tau_{p}$ are, respectively, the front of the aperiodic discharge current pulse $i_{d}(t)$ between levels (0.1-0.9) $I_{m a}$ and the duration of the aperiodic current pulse in the discharge circuit under study at a level of $0.5 \cdot I_{m a}$. It is useful to find the ratio of the form $\tau_{f} \approx t_{m a} / 1.6 \approx 0.625 \ln \left(\alpha_{2} / \alpha_{1}\right) /\left(\alpha_{2}-\alpha_{1}\right)$ [14] when finding the amplitude-time parameters (ATP) of the aperiodic pulse of the discharge current $i_{d}(t)$ of the HVES with CSE, where $t_{m a}$ is the time corresponding to the $I_{m a}$ amplitude of the unipolar current in the high-current circuit of the HVES with CSE.

With regard to the concept of the equivalent active resistance $R_{c}$ of the plasma channel of a spark used in (1), we mean by it a constant resistance averaged over time $t$, at which, when passing through the circuit of the HVES with CSE of the impulse discharge current $i_{d}(t)$, the same thermal energy, as well as on a real variable in time $t$ resistance of the spark discharge channel in the TES of the considered HVCAS. When determining the active resistance $R_{c}(t)$ of the plasma channel of a spark discharge in the general form of the variable in time $t$ in the investigated switch, we use the following classical relation [14]:

$$
R_{c}(t)=l_{c} /\left[\pi r_{c}^{2}(t) \gamma_{c}\right],
$$

where $r_{c}(t)$ is the radius of the plasma channel of spark discharge varying with time $t$, with constant length $l_{c}$ between the metal electrodes of the HVCAS; $\gamma_{c}$ is the averaged conductivity of low-temperature plasma in the channel of the switch spark.

The radius $r_{c}(t)$ of a single plasma spark channel in any design of the HVCAS varies, as is known, during the course of the impulse current $i_{d}(t)$ in the HVES discharge circuit with CSE in the range from zero to its maximum value $r_{c m}$ [1,9-12]. Initially, on the increasing part of the discharge current $i_{d}(t)$, this change occurs from zero to $r_{c m}$, and then on the falling part of this impulse current in the HVCAS circuit with $\mathrm{CSE}$ - from $r_{c m}$ to zero. Therefore, according to (4), the time variation curve $t$ of the value of the active resistance $R_{c}(t)$ of the plasma spark channel in the HVCAS can be approximated by a symmetric $U$-shaped curve characterized by its two maximum values at times $\mathrm{t}$ corresponding to zero current values $i_{d}(t)$ and equality $r_{c}=0$, and its one minimum value at time $t$, when the current $i_{d}(t)$ reaches its amplitude value and $r_{c}=r_{c m}$. Then, taking into account the corresponding change in (4) in time $t$ of the radial function of the form $f\left(r_{c}\right)=r_{c}{ }^{2}$ on the interval $\left[0 ; r_{c m}\right]$ and finding the average value for the equivalent and constant in time $t$ of the active resistance $R_{c}$ of a single plasma spark-gap channel in the investigated HVCAS, we obtain the following calculated expression:

$$
R_{c}=l_{c} /\left(\pi \gamma_{c} r_{c m}^{-1} \int_{0}^{r_{c m}} r_{c}^{2} d r_{c}\right)=3 l_{c} /\left(\pi r_{c m}^{2} \gamma_{c}\right)
$$

From (5), the proposed approach in the definition of $R_{c}$ implies the calculated ratio for the equivalent radius $r_{c e}$ of the plasma channel of a high-current spark in the HVCAS, equal to $r_{c e} \approx 0.577 \cdot r_{c m}$. The magnitude of the maximum radius $r_{c m}(\mathrm{~m})$ of the plasma channel of a spark discharge in an atmospheric pressure HVCAS is found from the well-known Braginskiy formula $[1,15]$ : 


$$
r_{c m}=0.093\left(I_{m}\right)^{1 / 3}\left(t_{m}\right)^{1 / 2}
$$

where $I_{m}, t_{m}$ are, respectively, the amplitude (A) of the pulse current $i_{d}(t)$ in the HVES discharge circuit with powerful CSE and the time (s) corresponding to this current amplitude.

From (5) and (6), the generalized expression for the equivalent active resistance $R_{c}(\Omega)$ of a single highcurrent plasma high-current spark discharge channel in the HVCAS placed in the HVES with CSE discharge circuit assumes the following final form:

$$
R_{c}=110.41 \cdot l_{c} /\left(\gamma_{c} I_{m}^{2 / 3} t_{m}\right) .
$$

When selecting (7) for the numerical values of $\gamma_{c}$ values will be based on its own computational and experimental data obtained earlier for plasma spark discharge air passage in the high-current circuit of HVES with powerful CSE [15]. According to the results of the studies presented in [15], for high-voltage atmospheric air switches at operating DC voltage up to $\pm 35 \mathrm{kV}$ and pulse currents of microsecond duration in the discharge circuit of HVCAS capacitor bank with a low resistance $R L$-load at their amplitude up to $\pm 250 \mathrm{kA}$, characteristic for a pulse components artificial lightning current [16], the averaged conductivity value $\gamma c$ low-temperature plasma in a cylindrical channel HVCAS spark in the first approximation, taking into account (5) and (6) numerically from 4000 to $5000(\Omega \cdot \mathrm{m})^{-1}$. It should be noted that these values $\gamma_{c}$ differ significantly from the corresponding values of the estimated temperature plasma conductivity of high spark air (about $20 \cdot 10^{3}$ $\left.(\Omega \cdot m)^{-1}\right)$ is given in [1] and the characteristic of the highly ionized plasma. Let us note that, at an electron temperature in the high-current spark discharge channel of the order of $10^{4} \mathrm{~K}$, which is characteristic of the channel of an air high-current spark in the investigated HVCAS [17], even in a dense plasma of the underwater spark discharge channel initiated by an electric explosion of a thin copper wire, the numerical values for its specific electric conductivity $\gamma_{c}$ channel depending on the pressure level is not more than a few thousand $(\Omega \cdot \mathrm{m})^{-1}[18]$.

Next, we estimate the value of thermal energy $W_{e}$, which is released on two massive metal electrodes of the considered HVCAS, schematically shown in Fig. 1. The determining effect on $W_{e}$ will be the power density $g_{c}(t)$ of the heat flux in the plasma spark channel between the cathode and the anode of the HVCAS. In the estimation of $g_{c}(t)$ in the proposed approach, a relationship of the form [17] can be used:

$$
g_{c}(t)=\delta_{d}(t) \cdot U_{a c},
$$

where $U_{a c}$ is the electrode voltage drop in the considered HVCAS, equal to the difference of electrical potentials at the interface between the «spark-metal» media.
It is known that the value of $U_{a c}$ in the investigated HVCAS with the main electrodes made of such traditional conductor materials as steel, copper, brass and beryllium bronze varies in a very narrow quantitative range, ranging from 5 to $10 \mathrm{~V}$ [19]. Thus, for steel grade Ст.3, the near-electrode voltage drop $U_{a c}$ is numerically about $6.1 \mathrm{~V}$, for copper $-8.6 \mathrm{~V}$, and for brass $-8.0 \mathrm{~V}$ [19]. Taking into account the assumed assumptions and (8) for the thermal energy $W_{e}$ dissipated on the working surfaces of the metal electrodes of the TES we can write the calculated expression:

$$
W_{e}=2 \pi \int_{0}^{\infty} g_{c}(t) r_{c}^{2}(t) d t=2 \pi U_{a c} \int_{0}^{\infty} \delta_{d}(t) r_{c}^{2}(t) d t=2 U_{a c} q_{c}
$$

where $q_{c}=\int_{0}^{\infty} i_{d}(t) d t-$ the module of the electric charge flowing through the plasma channel of the spark discharge in the high-current circuit of the HVES with powerful CSE and the metal electrodes of the investigated HVCAS.

It is seen from (9) that for the calculated determination of the thermal energy $W_{e}$ we need to first know the amount of electricity $q_{c}$ that has flowed through the electrodes of the HVCAS. Moreover, the desired value of $W_{e}$ is directly proportional to the electric charge $q_{c}$. When changing the impulse current $i_{d}(t)$ in the discharge chain of HVES with SNE according to the law of an exponentially damped sinusoid, the following relation can be used to calculate the charge $q_{c}$ :

$$
q_{c}=k_{d s} I_{m s} \omega^{-1}\left[(\delta / \omega)^{2}+1\right]^{-1} .
$$

At changing the impulse current $i_{d}(t)$ with respect to the aperiodic time dependence for $q_{c}$, we have:

$$
q_{c}=k_{d a} I_{m a}\left(\alpha_{2}-\alpha_{1}\right)\left(\alpha_{1} \alpha_{2}\right)^{-1} \text {. }
$$

One of the checks on the correctness of the calculation results for (10) and (11) for $q_{c}$ is the data obtained from the expression $q_{c}=C_{g} U_{g c}$, where $C_{g}$ and $U_{g c}$ are the electrical capacitance and charging voltage of the high-voltage capacitors of CSE, respectively.

Thus, by determining the value of the heat energy $W_{c}$ dissipated in the spark channel by (1) - (3) and (7) and calculating the thermal energy by the heat energy $W_{e}$ scattered at the cathode and the anode of the TES by (9) - (11), from the expression $W_{k}=W_{c}+W_{e}$ can find the total energy release in the high-current air circuit of the HVES discharge circuit with CSE.

3. Approximate calculation of the electrical erosion of electrodes in the HVCAS of the discharge circuit of the HVES with CSE. In the framework of this study, let us dwell on the estimated estimation of the electric erosion of the working surface of the metal electrode-anode HVCAS caused by a stream of free electrons accelerating in the longitudinal electric field of 
the channel, bombarding the indicated surface of the anode of the switch under consideration. In this case, for the thermal energy $W_{a}$, which is dissipated in the circular zone of the binding of the spark discharge channel with a radius $r_{c m}$ on the working surface of the anode of the HVCAS, one can, on the basis of (9), write the following relationship:

$$
W_{a}=U_{a c} q_{c} .
$$

On the other hand, for the sought value of the thermal energy $W_{a}$, based on the positions of thermal physics, the following calculated formula will hold true:

$$
W_{a}=M_{e}\left[C_{e}\left(\theta_{m}-\theta_{0}\right)+C_{m}\right] \text {, }
$$

where $M_{e}=d_{e} \cdot V_{e}$ is the mass of intensely heated by the pulsed discharge current $i_{d}(t)$ in the circular binding zone on the surface of the electrode electrode-anode of the HVCAS of the spark channel to the melting point $\theta_{m}$ of its material having the density $d_{e}$ and volume $V_{e} ; C_{e}, C_{m}$ are, respectively, the specific heat and specific heat of fusion of the anode material of the considered HVCAS.

The value of the volume $V_{e}$ of the melt and ejected outward by the magnetic pressure of the liquid metal of the switch, for one exposure of the spark channel to it, taking into account the assumed assumption about the geometric form of the crater of destruction on its working surface in the form of a ball segment, can be described by the following relation:

$$
V_{e}=0.5 \pi r_{c m}^{2} h_{e}
$$

where $h_{e}$ is the depth of the rupture crater with an outer radius $r_{c m}$ on the working surface of the HVCAS anode during the time of exposure to a spark from one highcurrent discharge of the HVES capacitor bank.

From (12) - (14), taking into account (6), the calculated expression for the maximum depth $h_{e}(\mathrm{~m})$ of a single erosion crater of destruction on the electrode-anode of the switch under consideration takes the following form:

$$
h_{e}=73.61 U_{a c} q_{c} d_{e}^{-1}\left[C_{e}\left(\theta_{m}-\theta_{0}\right)+C_{m}\right]^{-1}\left(I_{m}^{2 / 3} t_{m}\right)^{-1} .
$$

For the reduce the mass $M_{e}(\mathrm{~kg})$ of metal emitted outward by a high-current spark from the anode electrode for one spark discharge in the HVES circuit with CSE and the working air gap of the HVCAS in question, we obtain the following calculated ratio:

$$
M_{e}=U_{a c} q_{c}\left[C_{e}\left(\theta_{m}-\theta_{0}\right)+C_{m}\right]^{-1} .
$$

It follows from (16) that the calculated loss of the metal mass $M_{e}$ from the electrode-anode of the investigated switch for one discharge of powerful CSE in the HVES circuit is directly proportional to the charge $q_{c}$ that has flowed through the main electrodes of the HVCAS. Note that such dependence for $M_{e}$ was previously established experimentally for commutation in the HVES discharge circuit with CSE of large pulsed exponentially decaying sinusoidal currents of microsecond duration for copper, molybdenum and titanium electrodes of the HVCAS [20]. In the first approximation, for the loss of the $M_{e N}$ mass due to the anode electrode of the switch for $N$ spark discharges of the powerful CSE of the electrophysical unit through the HVCAS, one can use the calculated ratio of the form: $M_{e N} \approx N \cdot M_{e}$. In addition, we point out that when calculating the electrical erosion of the metal electrodecathode of the HVCAS, the calculated expressions (15) and (16) can be used.

4. Experimental verification of the results of calculating the electrical erosion of steel electrodes in the HVCAS discharge circuit of the HVES with ENE. This test was performed in the HVES discharge circuit with a powerful single-module CSE for a rated voltage of $\pm 50 \mathrm{kV}$ with nominal power capacity of its capacitor bank $W_{g 0} \approx 416 \mathrm{~kJ}$ (111 pieces of parallel-connected highvoltage capacitors of the type ИК-50-3) forming on the concentrated $R L$-load $\left(R_{l} \approx 10 \mathrm{~m} \Omega, L_{l} \approx 0.3 \mu \mathrm{H}\right)$ LIC of microsecond duration $[9,14]$. We will point out that the experimental HVES had the following electric parameters (up to the prefabricated steel buses of the CSE collector without taking into account the influence of the switch) $[9,14]$ : capacitance $C_{g}=333 \mu \mathrm{F}$; inductance $L_{g}=2.05 \mu \mathrm{H}$; active resistance $R_{g}=57 \mathrm{~m} \Omega$. To switch the energy used by the HVES to the CSE a cascade-type HVCAS was used for a rated voltage of $\pm 50 \mathrm{kV}$, containing two main massive hemispherical electrodes of radius $R_{e} \approx 61.5 \mathrm{~mm}$ and one controlling a massive spherical electrode $30 \mathrm{~mm}$ in diameter made of steel of grade Ст.3 (Fig. 2) [7, 9].

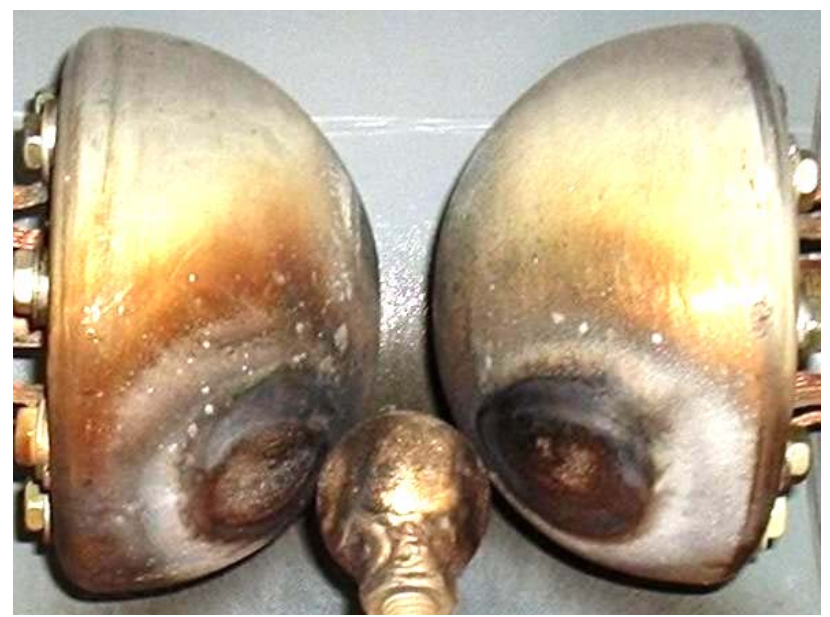

Fig. 2. Enlarged view of a three-electrode system of the cascade type HVCAS with two hemispherical massive main electrodes and one control electrode of a spherical steel Ст.3 marks on the rated voltage $\pm 50 \mathrm{kV}$ and a pulse microsecond current amplitude $I_{m}$ up to $\pm 300 \mathrm{kA}$ (type after a single exposure at its electrodes in steel HVES discharge circuit with powerful pulse CSE damped sinusoidal current frequency $\omega / 2 \pi=4.9 \mathrm{kHz}$ and amplitude of the first $I_{m s}=-202 \mathrm{kA} ; J_{a}=2,12 \cdot 10^{6} \mathrm{~J} / \Omega$; experimental channel radius value sparks $r_{c m} \approx 31 \mathrm{~mm}$ length channel spark $l_{c} \approx 13.5 \mathrm{~mm}$ )

At the charging voltage of high-voltage impulse capacitors of this CSE is equal to $U_{g c}= \pm 29.7 \mathrm{kV}$ and the energy stored in them is $W_{g}=147 \mathrm{~kJ}$, the working air gap between the control electrode of the HVCAS and its 
potential main electrode is $l_{c 1} \approx 9 \mathrm{~mm}$, and from the nonpotential side The main electrode of the switch, the working air gap was $l_{c 2} \approx 4.5 \mathrm{~mm}$. In this connection, in the experimental HVCAS, the length of the high-current spark was approximately $l_{c}=l_{c 1}+l_{c 2} \approx 13.5 \mathrm{~mm}$. After a high voltage igniting microsecond voltage pulse of amplitude of $\pm 100 \mathrm{kV}$ (its polarity corresponded to the charge polarity of the CSE capacitors) was applied to the control electrode of the HVCAS from a special generator $[7,9]$, an electrical breakdown of an air gap of length $l_{c 2}$ occurred, which resulted in the breakdown of an air gap of length $l_{c 1}$ and trip mentioned switch as a whole. As a result of triggering HVCAS between its steel electrodes a high-current air spark appeared, which destroys the working surfaces of the anode, cathode and control electrode of the switch. In Fig. 2 the results of such electrothermal action on these steel electrodes of the highcurrent plasma channel of an air spark discharge occurring in the HVCAS of the experimental HVES $\left(U_{g c}=-29.7 \mathrm{kV}\right)$ are shown, in the case of LIC flowing through them, whose oscillogram is shown in Fig. 3.

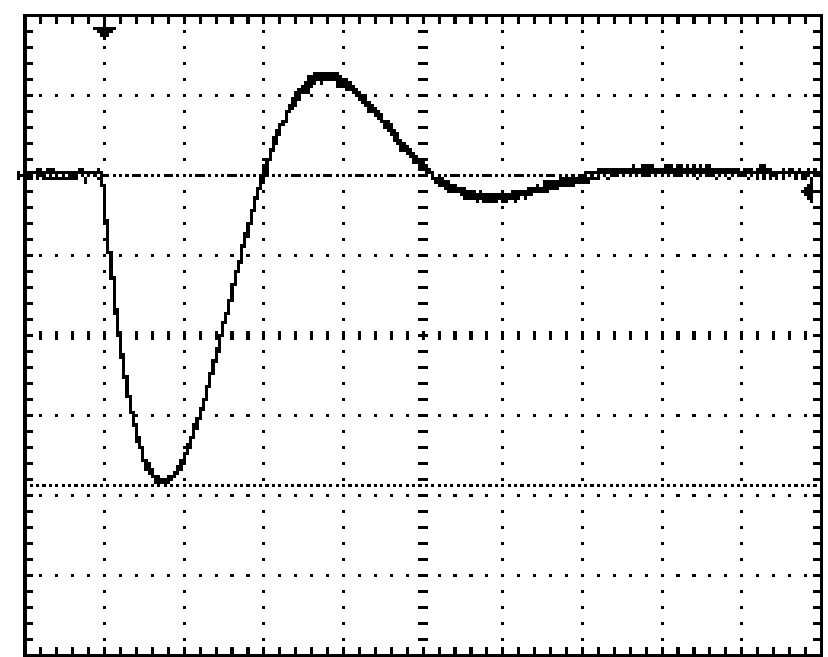

Fig. 3. . Oscillogram of a pulsed damped sinusoidal current $i_{d}(t)$ in the HVES discharge circuit with powerful CSE and a lowresistance concentrated $R L$-load, a switched cascaded HVCAS with two massive basic hemispherical electrodes and one control spherical electrode of Ст. 3 grade for a nominal voltage of \pm 50

$\mathrm{kV}$ and pulsed microsecond current of amplitude

$I_{m}$ up to $\pm 300 \mathrm{kA}\left(U_{g c}=-29.7 \mathrm{kV} ; W_{g}=147 \mathrm{~kJ} ; I_{m s}=-202 \mathrm{kA}\right.$; $\delta=13.00 \cdot 10^{3} \mathrm{~s}^{-1} ; \omega=30.79 \cdot 10^{3} \mathrm{~s}^{-1} ; k_{d s}=1.783 ; t_{m s}=36 \mu \mathrm{s} ; t_{0}=500$ $\mu \mathrm{s} ; J_{a}=2.12 \cdot 10^{6} \mathrm{~J} / \Omega ; q_{c}=9.93 \mathrm{C}$; vertical scale $-52.1 \mathrm{kA} /$ division; horizontal scale $-50 \mu \mathrm{s} /$ division).

Measurement of the ATP of the pulsed damped sinusoidal current $i_{d}(t)$ in the discharge circuit of the experimental HVES with powerful CSE was carried out using a measuring coaxial shunt of the ШК-300 type, certified by the state metrological service, with an intrinsic active resistance of about $R_{s} \approx 0.2 \mathrm{~m} \Omega$ and a conversion factor of about $K_{s} \approx 10,42 \cdot 10^{3} \mathrm{~A} / \mathrm{V}[10,14]$, and the digital storage oscilloscope Tektronix TDS 1012.
According to the diagram in Fig. 3 the oscillogram of the damped sinusoidal LIC $i_{d}(t)$ with the first half-wave of negative polarity in the discharge circuit of the HVES of its ATP at the total duration of the current pulse $t_{0}=500 \mu \mathrm{s}$ was approximately equal in absolute value: $I_{m s}=202 \mathrm{\kappa A}$; $\delta=13.00 \cdot 10^{3} \mathrm{~s}^{-1} ; \omega=30.79 \cdot 10^{3} \mathrm{~s}^{-1} ; k_{d s}=1.783 ; t_{m s}=36 \mu \mathrm{s}$.

To the above-mentioned ATP discharge current $i_{d}(t)$ in the circuit of the experimental HVES with CSE according to (6) corresponds to the calculated maximum radius $r_{c m}$ of the plasma channel of the air spark in the investigated switch, equal to about $32.7 \mathrm{~mm}$. From the experimental data presented in Fig. 2, it follows that the maximum radius $r_{c m}$ of the circular crater hole on the working surfaces of the main steel electrodes in the HVCAS of the applied experimental HVES with the CSE is approximately $31 \mathrm{~mm}$. It can be seen that the calculated and experimental results for the radius $r_{c m}$ of the binding zone of the plasma channel of the high-current spark on the working steel surfaces of the anode and the cathode of the said HVCAS differ within $5 \%$. In this connection, we can say that the experimental data obtained by us confirm the operability of the calculated Braginskiy formula for the plasma channel of an air spark used in [1, 15] for practical application in the LIC region of microsecond time range.

The results of a survey of the working hemispherical surfaces of the steel anode and the cathode of the HVCAS, shown in Fig. 2, indicate that in the case under consideration the geometrical shape of single circular craters of destruction with a radius of $r_{c m} \approx 31 \mathrm{~mm}$ in the areas of attachment of a high-current air spark to them was close to the shape of the spherical segment, and their experimental depth he did not exceed $7 \mu \mathrm{m}$. In accordance with (10) and (15) with given initial data $\left(I_{m s}=202 \mathrm{kA} ; \delta=13.00 \cdot 10^{3} \mathrm{~s}^{-1}\right.$; $\omega=30.79 \cdot 10^{3} \mathrm{~s}^{-1} ; k_{d s}=1.783 ; t_{m s}=36 \mu \mathrm{s} ; U_{a c}=6.1 \mathrm{~V}$; $d_{e}=7870 \mathrm{~kg} / \mathrm{m}^{3} ; \quad C_{e}=460 \mathrm{~J} /\left(\mathrm{kg} \cdot{ }^{\circ} \mathrm{C}\right) ; C_{m}=84 \cdot 10^{3} \mathrm{~J} / \mathrm{kg} ;$ $\left.\theta_{0}=0{ }^{\circ} \mathrm{C} ; \theta_{m}=1500{ }^{\circ} \mathrm{C}[8,10]\right)$ we find that in our case the calculated maximum depth $h_{e}$ for erosion craters of failure at their design radius $r_{c m} \approx 32.7 \mathrm{~mm}$ on the working surfaces of the massive main steel electrodes of HVCAS when flowing through the switchboard in a single pulse discharge of a powerful CSE $\left(U_{g c}=-29.7 \mathrm{kV}\right.$; $W_{g}=147 \mathrm{~kJ}$ ) in the high-current circuit of the experimental WEFU electric charge $q_{c}=9.93 \mathrm{C}$ will be approximately $5.9 \mu \mathrm{m}$. As we can see, the discrepancy between the calculated and experimental values for $h_{e}$ with respect to the HVCAS used is no more than $16 \%$. We will point out that in this case the calculated loss of the metal mass $M_{e}$ from the working surface of the steel electrode-anode in accordance with (16) is approximately $78.2 \mathrm{mg}$. Then, for the specific electric erosion of $M_{e} / q_{c}$ of the steel electrode-anode of the considered HVCAS, we obtain a numerical value equal to about $78.7 \cdot 10^{-4} \mathrm{~g} / \mathrm{C}$. To compare this specific electroerosion wear $M_{e} / q_{c}$ of the massive steel main 
electrodes of the investigated HVCAS with known similar electrophysical data, we note that in highcurrent high-voltage gas-discharge switches for nominal voltage of $\pm 50 \mathrm{kV}$ type РГУ1-50-100 with the main electrodes from the metal composition «tungstencopper», designed for commutation of damped sinusoidal microsecond LIC with duration $t_{0} \leq 100 \mu \mathrm{s}$ and an amplitude of $I_{m s}$ up to $100 \mathrm{kA}$, a specific electroerosive wear of their composite anode and a cathode But is almost two orders of magnitude smaller numerical value and is approximately $4.4 \cdot 10^{-5} \mathrm{~g} / \mathrm{C}$ [21].

\section{Conclusions.}

1. In accordance with the proposed new engineering approach to approximate calculated energy estimates and electrical erosion in large metal electrodes in the HVCAS of atmospheric pressure, performing switching in a discharge circuit of the HVES with powerful CSE, only necessary data on the electrical and thermal characteristics of the anode metal and its cathode TES averaged conductivity $\gamma_{c}$ of low-temperature plasma in a channel of the air spark discharge between the electrodes of the HVCAS ATP of pulsed discharge current $i_{d}(t)$ in high-current circuit of the HVES with CSE.

2. It has been established that when calculating the thermal energy $W_{c}$ that is dissipated in the air spark of the investigated HVCAS, a new electrophysical concept concerning the equivalent active resistance $R_{c}$ of a pulsed air spark that is constant during the whole process of oscillating or aperiodic discharge of the CSE of the HVES on the electric load can be used. The original calculation formula (7) is obtained to find the approximate numerical value of $R_{c}$ from the known data for $\gamma_{c}$, the length $l_{c}$ of the air spark channel, and the ATP of pulsed sinusoidal (aperiodic) discharge current of the CSE in the highcurrent HVES circuit on the $R L$-load.

3. The performed high-current experiments in the HVES discharge circuit with powerful CSE confirmed the reliability of certain obtained and used formulas calculation relations (in particular, formulas (6), (10), (15) and (16)) for approximate estimation of energy dissipation and electric erosion of massive metal electrodes of TES in the investigated HVCAS of atmospheric pressure.

\section{REFERENCES}

1. Dashuk P.N., Zayents S.L., Komel'kov V.S., Kuchinskiy G.S., Nikolaevskaya N.N., Shkuropat P.I., Shneerson G.A. Tehnika bol'shih impul'snyh tokov i magnitnyh polej [Technique large pulsed currents and magnetic fields]. Moscow, Atomizdat Publ., 1970. 472 p. (Rus).

2. Bostic W., Nardi V., Zucker O. Nakoplenie i kommutacija energii bol'shih plotnostej [Accumulation and commutation of energy of high densities]. Moscow, Mir Publ., 1979. 474 p. (Rus).

3. Baranov M.I. Application of new gas-discharge and solidstate semiconductor switchboards in high-current circuits of powerful high-voltage electrophysical installations. Electrical engineering \& electromechanics, 2009, no.1, pp. 55-58. (Rus). doi: 10.20998/2074-272X.2009.1.11.

4. Baranov M.I. Application of new vacuum switchboards in high-current circuits of powerful high-voltage electrophysical installations and emergency protection circuits of power electrical equipment. Electrical engineering \& electromechanics, 2009, no.3, pp. 5-10. (Rus). doi: 10.20998/2074-272X.2009.3.01.

5. Boyko N.I., Evdoshenko L.S., Zarochentsev A.I., Ivanov V.M., Tour A.N. High-Voltage Spark Gaps for Technological Purposes. Instruments and Experimental Technique, 2001, vol.44, no.2, pp. 204-212. doi: 10.1023/a:1017515003483.

6. Baranov M.I., Bocharov V.A., Zyabko Yu.P., Melnikov P.N. High-voltage strong current spark switches for high-voltage impulse and current generators. Tekhnichna elektrodynamika, 2003, no.3, pp. 41-47. (Rus).

7. Baranov M.I., Koliushko G.M., Kravchenko V.I., Nedzel'skii O.S., Nosenko M.A. High-voltage high-current airfilled spark gaps of an artificial-lightning-current generator. Instruments and Experimental Techniques, 2008, vol.51, no.6, pp. 833-837. doi: 10.1134/s0020441208060109.

8. Kuhling H. Spravochnik po fizike. Per. s nem. [Dictonary on Physics. Translated from German]. Moscow, Mir Publ., 1982. 520 p. (Rus).

9. Baranov M.I., Koliushko G.M., Kravchenko V.I., Nedzel'skii O.S., Dnyshchenko V.N. A Current Generator of the Artificial Lightning for Full-Scale Tests of Engineering Objects. Instruments and Experimental Technique, 2008, vol.51, no.3, pp. 401-405. doi: 10.1134/s0020441208030123.

10. Baranov M.I., Kniaziev V.V., Rudakov S.V. Calculation and experimental estimation of results of electro-thermal action of rationed by the international standard IEC 62305-1-2010 impulse current of short blow of artificial lightning on the thinwalled coverage from stainless steel. Electrical engineering \& electromechanics, 2017, no.1, pp. 31-38. (Rus). doi: 10.20998/2074-272X.2017.1.06.

11. Raiser Yu.P. Fizika gazovogo razrjada [Physics of gas discharge]. Moscow, Nauka Publ., 1987. 592 p. (Rus).

12. Namitokov K.K. Elektroerozionnye javlenija [Electroerosion phenomena]. Moscow, Energia Publ., 1978. 456 p. (Rus).

13. Butkevich G.V., Belkin G.S., Vedeshenkov N.A., Zhavoronkov M.A. Elektricheskaja erozija sil'notochnyh kontaktov $i$ elektrodov [Electrical erosion of high current contacts and electrodes]. Moscow, Energia Publ., 1978. 256 p. (Rus).

14. Baranov M.I. Izbrannye voprosy elektrofiziki. Tom 3: Teorija i praktika elektrofizicheskih zadach [Selected topics of Electrophysics. Vol. 3: Theory and practice of electrophysics tasks]. Kharkiv, Tochka Publ., 2014. 400 p. (Rus).

15. Lozanskiy E.D., Firsov O.B. Teorija iskry [Theory of spark]. Moscow, Atomizdat Publ., 1975. 272 p. (Rus).

16. SAE ARP 5412: 2013. Aircraft Lightning Environment and Ralated Test Waveforms. SAE Aerospace. USA, 2013. pp. 1-56.

17. Baranov M.I. An approximate calculation of the maximum temperature of the plasma in high-current high-voltage spark discharge channel switch air atmospheric pressure. Tekhnichna Elektrodynamika, 2010, no.5, pp. 18-21. (Rus).

18. Gulyi G.A. Nauchnye osnovy razriadno-impul'snykh tekhnologii [Scientific basis of the discharge-pulse technology]. Kiev, Naukova Dumka Publ., 1990. 208 p. (Rus). 
19. Abramov N.R., Kuzhekin I.P., Larionov V.P. Characteristics of penetration of the walls of metal objects when exposed to lightning. Electricity, 1986, no.11, pp. 22-27. (Rus).

20. Belkin G.S., Kiselev V.Ya. Influence of electrode material on erosion at strong currents. Technical Physics, 1967, vol.37, no.5, pp. 977-979. (Rus).

21. Ermilov I.V. Development of a complex of high-voltage high-current equipment of a new generation for magnetic-pulse processing of materials. Trudy mezhdunarodnoi nauchnotekhnicheskoi konferentsii MIOM-2007 [Proceedings of the International Scientific and Technical Conference MPPM2007]. Russian Federation, Samara, SGAU, 18-19 September, 2007, pp. 88-98. (Rus).
M.I. Baranov ${ }^{1}$, Doctor of Technical Science, Chief Researcher, S.V. Rudakov ${ }^{2}$, Candidate of Technical Science, Associate Professor,

${ }^{1}$ Scientific-\&-Research Planning-\&-Design Institute «Molniya», National Technical University «Kharkiv Polytechnic Institute», 47, Shevchenko Str., Kharkiv, 61013, Ukraine, phone +380577076841 , e-mail: eft@kpi.kharkov.ua

${ }^{2}$ National University of Civil Protection of Ukraine, 94, Chernyshevska Str., Kharkiv, 61023, Ukraine, phone+38057 7073438, e-mail: serg_73@i.ua

\section{Received 27.03.2017}

How to cite this article:

Baranov M.I., Rudakov S.V. An approximate calculation of energy dissipation and electric erosion of electrodes in the high-voltage high-current air switch of atmospheric pressure. Electrical engineering \& electromechanics, 2017, no.3, pp. 32-39. doi: 10.20998/2074-272X.2017.3.05. 